\title{
Mechanisms of Action of Human Mesenchymal Stem Cells in Tissue Repair Regeneration and their Implications
}

\author{
Manisha Singh, Suchi Gupta, Sonali Rawat, Swati Midha, Krishan Gopal Jain, \\ Manu Dalela, Sujata Mohanty \\ Stem Cell Facility (DBT- Centre of Excellence for Stem Cell Research), \\ All India Institute of Medical Sciences, New Delhi.
}

\begin{abstract}
Cell replacement therapy holds a promising future in the treatment of degenerative diseases related to neuronal, cardiac and bone tissues. In such kind of diseases, there is a progressive loss of specific types of cells. Currently the most upcoming and trusted cell candidate is Mesenchymal Stem Cells (MSCs) as these cells are easy to isolate from the tissue, easy to maintain and expand and no ethical concerns are linked. MSCs can be obtained from a number of sources like bone marrow, umbilical cord blood, umbilical cord, dental pulp, adipose tissues, etc. MSCs help in tissue repair and regeneration by various mechanisms of action like cell differentiation, immunomodulation, paracrine effect, etc. The future of regenerative medicine lies in tissue engineering and exploiting various properties to yield maximum output. In the current review article, we have targeted the repair and regeneration mechanisms of MSCs in neurodegenerative diseases, cardiac diseases and those related to bones. Yet there is a lot to understand, discover and then understand again about the molecular mechanisms of MSCs and then applying this knowledge in developing the therapy to get maximum repair and regeneration of concerned tissue and in turn the recovery of the patient.
\end{abstract}

Keywords: Differentiation, immunomodulation, exosomes, tissue engineering.

\section{Introduction}

Mesenchymal Stem Cells (MSCs) hold enormous potential in the management of tissue degeneration related to neuronal or cardiac or bone tissues of the human body. Their tissue regenerative potential has been explored in detail by various research groups. Also several investigators have studied their mechanisms of action pertaining to their effect in tissue repair and regeneration.

The evidence for the presence of stem cell population in the bone marrow (BM) that has the capacity to produce non-hematopoietic progeny emerged in the mid-1960's, after the pioneering work of Friedenstein et al (1-3). This group characterized BM derived cells of mesenchymal origin (hence called Mesenchymal Stromal/ Stem Cells) which are the plastic adherent cells, immunologically naive and are capable of forming clonal fibroblast colony (CFU-f). These workers also described a fundamental technique of isolation of BM-MSCs by simply plating bone marrow with suitable medium onto culture dish and discarding supernatant (non-adherent

Correspondence : Prof. Sujata Mohanty, Stem Cell Facility, 1st Floor, ORBO Complex, All India Institute of Medical Sciences, Ansari Nagar, New Delhi-110029. Tel: 91-9868398194/ 919810291336.Fax:91-11-26588641/91-11-26588603.Email:drmohantysujata@gmail.com. 
hematopoietic cells). After 24 hrs, only adhered cells are left $(3,4)$. Along with these findings, several independent studies proved the multipotent characteristic of MSCs and their capacity to differentiate into cells of mesodermal lineage, including osteoblasts (5-9), chondroblasts $(5,10,11)$, adipocytes $(7,12)$ and myoblasts (13). Therefore, to characterize MSCs, they need to have multipotent capability to differentiate into osteoblasts, chondroblasts and adipocytes and should bear a defined set of markers like CD105, CD90, CD73, CD29 and negative for HLA class II, CD34, CD45 (14).

MSCs are unique type of stem cells that have capability of differentiating into different cell types and can rescue or repair the injured or degenerating cells. The most unique feature of these cells are capability of expression of immunomodulatory and tropical factors. These factors can augment and modulate both the adaptive and innate immune responses as all of these pertain to the regenerative paradigm. The mechanisms of damaged tissue repair is associated with activation of inflammatory cells, including all adaptive and innate immune cells, i.e. T cells, B cells, which are further chemotaxis by damaged, necrotic, apoptotic cells and stroma. In response, phagocytes also secrete or mediate the response by tumor necrosis factor alpha (TNF- $\alpha)$, interleukin 1 beta (IL-1 $\beta$ ), chemokines and leukotrienes. Thus, c o mbination of inflam atory molecules/immune cells with endothelial cells and fibroblast, leads the changes in microenvironment which results in the mobilization and differentiation of MSCs in exchange of injured tissue cells (15-18).

Stem cells have also been studied in a number of studies and have shown immense potential in repair and regeneration. There have been studies where it was proposed that these MSCs are emerging as key players in regenerative medicine. Currently, there are 344 registered clinical trials in different phases across the world (19). However, recent research has shown that stem cells implanted in various studies have low and transient homing to the site of injury and this has given rise to paracrine effect where stem cells not only release soluble factors, but also extracellular vesicles like exosomes which elicit similar biological activity to the stem cells themselves (20).

Recent advances in stem cell research have appreciably influenced the background of regenerative medicine and tissue engineering. The success of stem cell-based technologies is due to its precise and reproducible control and its lineage differentiation and specification. Although stem cells have potential to regenerate tissues, current research scenario is shifted towards developing fully functional organs and various clinical uses including cell or tissue repair through three-dimensional printing methods.

Hence, this review article will provide a brief of the recent advances in the field of understanding mechanisms of action of MSCs in tissue regeneration as described above.

\section{Mechanisms of Action of Stem Cells}

\section{a. Differentiation into Cell Types}

Neuronal differentiation potential of human Mesenchymal Stem Cells ( $h M S C s$ )

Several research groups have explored the neuronal differentiation potential of MSCs. The reports of differentiating stromal cells into neural cells/ neurons were reported by SanchezRamos et al and Woodbury et al $(21,22)$. After this, several research groups started exploring the differentiation potential of MSCs by using different strategies, viz. using chemicals like Dimethyl Sulphoxide (DMSO)/ Butylated Hydroxyanisole (BHA), 3-isobutyal-1methylxanthine (IBMX)/dbcAMP, all-trans retinoic acid (ATRA), safrole oxide, etc. (23-26), growth factors like fibroblast growth factor 8 (FGF8), sonic hedgehog (SHH), nerve growth factor (NGF), along with epidermal growth factor (EGF) and FGF2, etc. (27-32), 
conditioned media or co-culturing with brain cells $(21,33,34)$, genetic engineering $(35,36)$, and recently by reprogramming cells and generating induced pluripotent stem cells (37, 38) and by using different kinds of scaffolds for mimicking the matrix $(39,40)$.

With the developing need to treat Parkinson's disease by a method other than conventional administration of L-DOPA, the cell replacement therapy emerged as a potential solution. The idea to differentiate stem cells into dopamine producing neuronal cells and then transplanting them into the patients came up as an upcoming field to explore. The idea emerged after successful transplantation of embryonic stem cells (ESC) into newborn rat, followed by a series of such studies later by various research groups (41-43). Starting from early 2007 and 2009, MSCs were differentiated using cocktails of cytokines or/and growth factors or/and chemical reagents, etc. (44-50). Various combinations of induction media cocktails using SHH, FGF 8, FGF2, EGF, brain-derived neutrotrophic factor (BDNF), ATRA, IBMX, cyclic adenosine 3', 5'-monophosphate (cAMP) and forskolin have been applied for in vitro differentiation of stem cells.

\section{Cardiac differentiation potential of hMSCs}

Trans-differentiation of MSCs has been proposed as one of the major mechanisms which participate in damage repair of cardiac tissue caused by myocardial infarction (51). MSCs have been differentiated into cardiomyocytes in vitro using various inducers such as 5-Aza, Transforming growth factor- $\beta 1$ (TGF- $\beta 1$ ), DMSO, etc. or co-culture method. Among them, 5 -Aza is the most studied inducer for cardiac differentiation of MSCs (52). However, their translational value is limited due to its demethylating properties. TGF- $\beta 1$, oxytocin and other small molecules including Bone Morphogenetic Proteins (BMPs) have also been used which are devoid of notable side-effects. Upon in vitro differentiation, these cells show morphological similarities with cardiomyocytes, like flattening of cells, formation of intercalated discs, bi-nucleation or multi-nucleation and expression of cardiomyogenic markers like myosin light chain, myosin heavy chain, actinin, troponin I, etc. In spite of numerous available protocols, till date no induction protocol has resulted in generation of electro-physiological functionality in cardiomyocytes from adult MSCs $(53,54)$. Additionally, their poor survival and engraftment at the injury site, questions the translational efficacy of this method.

It has also been demonstrated that oxytocin or TGF- $\beta 1$ treatment works as an efficient cardiomyogenic inducers $(55,56)$. In a previous study, our group established that TGF$\beta 1$ is a potent cardiogenic inducer in BM-MSCs. Upon 14 days treatment, they expressed similar levels of cardiac-specific marker as compared to those treated with 5-Aza for 30 days (56). Also, priming of BM-MSCs with conditioned media of cardiac biopsy tissue increases the level of cardiac-specific markers like myosin light chain and cardiac troponin I (57). Besides the use of exogenous inducers, co-culture with cardiac cells has also been studied for MSC cardiac differentiation $(58,59)$. Injured myocardium is known to recruit MSCs for tissue regeneration, but is not sufficient if the infarcted region is large. Therefore, in such cases exogenous MSCs are injected directly to the peri-infarct area. After intra-myocardial injection, they have been found to engraft and make contacts with native cardiomyocytes (60). Additionally, the expression of connexin 43 (junctional protein) in MSCs may help them in electro-mechanical coupling with host cardiomyocytes (61).

In spite of so much research, authentication of this phenomenon is incomplete and other mechanisms including paracrine factors, mitochondrial transfer and cell fusion have been proposed as important players in the regeneration ability of MSCs. 


\section{Osteogenic potential of hMSCs}

The existence of osteogenic stem cells within the bone marrow stroma was first described over fifty years ago, when Petrakova et al (62) obtained an osseous tissue by implanting pieces of bone marrow under kidney capsule.

Various protein-based cytokines and growth factors such as bone morphogenetic proteins (BMP) $(63,64)$, TGF- $\beta 1(65,66)$, interleukin-6 (IL-6) (67), growth hormone (68), leptin (69), sortilin (70), and transglutaminase (71) have been suggested to be involved in regulating osteogenesis. Besides these, several synthetic chemical compounds such as dexamethasone (72), $\beta$-glycerophosphate (73), L-ascorbic acid (74), prostaglandin E2 $(75,76)$, 1,25-dihydroxyvitamin D3 (77), TAK-778 (78), and a family of compounds known as the statins $(79,80)$ have also been identified as key soluble factors which induce osteogenic differentiation of MSCs in vitro. In addition to supplements added to the basal medium, other techniques to optimize osteogenic induction have been investigated as well. In some studies, mechanical stress (81), pulsed electromagnetic field (82), and hydrostatic pressure (83) were added to the osteogenic factors, while in others these factors were used to stimulate osteogenic differentiation without osteogenic induction supplements. The process of osteoblasts differentiation can be subdivided into three stages of proliferation, extracellular matrix synthesis and maturation, mineralization.

Each stage is characterized by expression of distinguishing osteoblast markers. The most frequently used markers of osteoblast differentiation are alkaline phosphatase (ALP), collagen type 1 (Col 1), osteopontin (OPN), bone sialoprotein (BSP), osteocalcin $(\mathrm{OCN})$ and PTH/PTHrp receptor (PTHR). In general, ALP, BSP and Col 1 are early markers for osteoblast differentiation, while PTHR and OCN appears late, parallel with mineralization (84).
Transcription factor, Runx 2 is a master regulator of osteogenic differentiation. It regulates the differentiation of MSCs towards osteogenic lineage by two independent signalling pathways via TGF- $\beta 1$ and BMP 2 (85, 86). Along with Runx2, BMP2 and distal-less homeobox 5 (Dlx5) commit MSCs towards the osteogenic lineage. BMP2 induces the expression of osterix independent of Runx2 (87). Following commitment, MSCs are differentiated into pre-osteoblasts. These preosteoblasts express Runx2, D1x5, msh homeobox homologue 2 (Msx2), P2Y4 and P2Y14 $(88,89)$, and few markers of osteoblasts such as ALP, Col 1, and OPN, but their expression is weaker than that in immature osteoblasts. ALP is one of the early proteins that regulate bone mineralization. $\beta$-Catenin, Runx 2 , and osterix differentiate pre-osteoblasts into immature osteoblasts. These are spindle shaped cells and secrete bone matrix protein, bone sialoprotein, and OPN (90). At later stages, Runx2 inhibits the maturation of osteoblasts (91). Osterix causes the terminal maturation of osteoblasts and induces OCN expression (92). When osteoblasts are completely differentiated they become cuboidal and produce a selfmineralized organic matrix (93). The Golgi bodies and rough endoplasmic reticulum are well developed in mature osteoblasts as a result of increased need for protein production. The expression of OPN is reduced in mature osteoblasts; while the expression of other proteins such as P2X5 (89), ALP (94), Col 1 (94, 95), and OCN (95) is increased.

\section{b. Immunomodulatory Effect of MSCS}

MSCs are unique type of stem cells that have capability of differentiating into different cell types and can rescue or repair the injured or degenerating cells. The most unique features of these cells are capability of expression of immunomodulatory and tropical factors. These factors can augment and modulate both the adaptive and innate immune responses as it pertains to the regenerative paradigm (96). The mechanisms of damaged tissue repair is 
associated with activation of inflammatory cells, including all adaptive and innate immune cells, i.e. T cells, B cells, which are further chemotaxis by damaged, necrotic, apoptotic cells and stroma. In response, phagocytes also secrete or mediate the response by TNF- $\alpha$, IL- $1 \beta$, chemokines and leukotrienes. Thus, c o mbination of inflam atory molecules/immune cells with endothelial cells and fibroblast, leads the changes in microenvironment which results in the mobilization and differentiation of MSCs in exchange of injured tissue cells (97). The mobilized MSCs can be taken from bone marrow or from the nearby vicinity of the injured tissue. However, the concert mode of actions for homing and recruitment to the injury site are not known. In response to injured tissue microenvironment, MSCs secret many factors, including tropical and immunomodulatory factors such as EGF, FGF, platelet-derived growth factor (PDGF), TGF- $\beta$, vascular endothelial growth factor (VEGF), hepatocyte growth factor (HGF), IL-10, Indoleamine 2, 3dioxygenase (IDO), chemokine ligand-5 (CCL5 ) or regulated on activation, normal $T$ cell expressed and secreted (RANTES), prostaglandin E2, and nitric oxide (NO), insulin growth factor-1 (IGF-1), angiopoietin-1 (Ang$1)$, keratinocyte growth factor (KGF) and stromal cell- derived factor-1 (SDF-1) $(19,20)$. In return, the growth factors help the development of fibroblast, endothelial cells and progenitor cells near the injured tissue area to carry out the tissue regeneration and repair. Another known mechanism for repair and regeneration by MSCs, includes the cell to cell contact. MSCs and immune cells interaction induces the secretion of anti-inflammatory factors such as IL-10 which inhibits the T cell proliferation and further in line upregulates the human leukocyte antigen-G5 (HLA-G5) secretion and in response it helps in diminishing the activated $\mathrm{T}$ cells and natural killer $(\mathrm{NK})$ cell cytotoxicity (98-100).

There is another class of paracrine trophic factors like Ang-1, VEGF, HGF, EGF, PDGF,
FGF, KGF and TGF- $\beta$, to affect the endothelial cells and initiating angiogenesis through their potential to promote endothelial cell proliferation and production of extracellular matrix, which helps in reduction of endothelial permeability and inhibit the interaction between leukocytes and endothelial cells (101).

\section{Clinical status}

A plethora of studies of animal model and translational studies have identified the capability of hMSCs to home to sites of injury and/or inflammation, thus adding to their use for therapeutic purposes. According to the available database at National Institute of Health (NIH) clinical trial registry (https://clinicaltrials.gov/), as of April 2016, there were over 500 MSCrelated clinical trials registered. Surprisingly, while the immunomodulatory properties of MSCs have only more recently been identified, nearly half of all registered clinical trials-230 trials or $42 \%$ of all registered trials-are being conducted for immune-/inflammation- mediated diseases. Different tissue sources may also play an important role in terms of different diseases, with the most explored and reported source being adult BM-MSCs (41.2\%). However, other tissue and fetal source MSCs are also popular choices, with $16.3 \%$ of trials using adiposederived MSCs, and $21.1 \%$ of trials using fetalsource MSCs which includes MSCs isolated from umbilical cord, umbilical cord blood, and placenta (102). While $32.5 \%$ of all trials specify the use of autologous sources, over $50.9 \%$ of trials appear to use allogeneic sources, i.e. trials which use fetal-source MSCs on adult patients. Unspecified donor sources account for approximately $16.7 \%$ of trials.

hMSCs are promising as a means of augmenting brain repair by paracrine signalling. During the brain injury, microglia are the first type of cell in inflammatory cascade followed by cytokines rush in the injury area. The proinflammatory M1 phenotype of microglia is associated with tissue destruction, whereas the inflammatory M2 phenotype of microglia 
facilitates repair and regeneration. MSC therapy may improve outcomes of ischemic stroke, neural trauma, and heatstroke by inhibiting the activity of M1 phenotype of microglia but augmenting the activity of M2 phenotype of microglia (103).

The positive results seen in preclinical animal studies have largely not yet translated into clinical efficacy. Clearly, there is still much to learn and optimize with regards to the in vivo interactions of MSCs in human pathological states. As we improve our understanding on the mechanistic properties of MSC immunomodulation, we also need to clarify patho-physiological details and subsets within disease entities to better tailor MSC therapy. One important aspect is to delineate tissue-specific functional different in MSCs from difference sources; the current International Stem Cell Therapy (ISCT) standardization does not include immune-related functional tests or more detailed molecular validation.

\section{c. Paracrine Mechanism of Action of MSCS}

Stem cells have been investigated in a number of studies and shown to have immense potential in repair and regeneration. There have been studies where it was proposed that these MSCs are emerging as key players in regenerative medicine (19). Currently, there are 344 registered clinical trials in different phases across the world (104). However, recent research has shown that stem cells implanted in various studies have low and transient homing to the site of injury and this has given rise to paracrine effect where stem cells not only release soluble factors, but also extracellular vesicles like exosomes which elicit similar biological activity to the stem cells themselves (20). These extracellular vesicles such as exosomes secreted by MSCs carry proteins and RNAs that help in rescuing and repairing of the damaged or diseased tissues. Amongst RNA, microRNA (miRNA) specifically have been shown to play central role in many diseases. Aberrant miRNA expression is an emerging theme for a wide variety of diseases, highlighting the fundamental role played by miRNAs in both physiological and pathological states. Therefore repairing of diseased tissues via exosome delivery (for miRNA) has inspired an alternative approach in regenerative medicine, i.e. translating the potential clinical applications based on exosomes secreted by the stem cells rather than the stem cells themselves . Initial studies using these MSCs were in cardiovascular diseases where it was first observed that condition media of these MSCs has paracrine effect and help in repair and regeneration. In 2010 it was first investigated in a mouse model of myocardia 1 ischemia/reperfusion injury that the condition media contain extracellular vesicles called exosomes (105). Following this, there were a large number of studies where these exosomes were isolated, characterized and studied in different disease models. To mention a few are: liver fibrosis, neurodegenerative diseases, kidney diseases, etc. In all these studies, MSCs derived exosomes have shown to elicit similar biological repair activity as that of MSCs themselves. Exosomes content have also been extensively studied including proteomics and RNA sequencing. It was observed that there is specific sorting of these biological molecules into these vesicles. Most of these studies related to the exosome profiling can be found in database of exosomal proteins and miRNAs at ExoCarta (www.exocarta.org). All these studies have successfully identified exosomes derived from MSCs as alternative source for therapeutic potential. These exosome due to their small size have vast applications like can cross blood brain barrier and are being studied in various neurodegenerative diseases. One such study has shown that MSCs-derived exosomes carry neprilysin protein which have therapeutic relevance in Alzheimer's, diseases (106-107). With recent advancements in research and technology, these exosomes may be new beacon for cell free therapy, where the content of these exosomes can be modulated as per the requirement and used as drug delivery system. These exosomes can be used for off the shelf 
therapeutic purposes. Although a lot has been known about these exosomes, but few basic questions and problem still needs to be tackle before these exosomes can be successfully taken up to therapeutic study (108-109). These include standardized protocol for their isolation and characterization. Mass production for wide scale study is the current challenge that needs to be answered so far.

\section{d. Tissue Engineering and MSCs}

\section{Bone tissue engineering}

With the huge plethora of orthopaedic deformation cases occurring everyday, tissue engineering and stem cell researchers have been on a quest to develop clinically relevant bone graft equivalents. While autologous/allogenic grafts are still the gold standard for a complex bone injury, their advantages are outweighed by limited supply and associated health risks. Therefore, to recapitulate the osteoinductive properties of bone grafts, current scaffold-based bone tissue engineering relies upon bioinspired approaches to accommodate the requirements of the cultured cells to guide adhesion, proliferation, migration, differentiation and tissue morphogenesis.

Standard tissue engineering strategy involves culturing osteoprogenitors onto $3 \mathrm{D}$ scaffolds with appropriate osteoinductive factors for promoting new bone synthesis. Osteogenic potential of various stem cells including BM-MSCs, adipose tissue-derived stem cells (ADSCs), ESCs, umbilical cord blood-derived mesenchymal stem cells (UCMSCs), dental pulp stem cells (DPSCs) and induced pluripotent stem cells (iPSCs) is being utilized (110). However, appropriate use of stem cells to engineer artificial bone grafts requires proper isolation and standardization protocols for controlled differentiation of cells into osteoblasts or terminal osteocytes. Wang et al (111) compared the osteogenic differentiation potential of hBMSCs, hiPSCs and hUCMSCs using $3 \mathrm{D}$ calcium phosphate cement (CPC). In vitro results demonstrated high cell viability and enhanced osteogenic expression (Runx2, Col 1, OCN) across all groups; however, de novo bone formation in rat cranial defects demonstrated highest hiPSCs and lowest for BMSCs. Moreover, cell-laden 3D constructs demonstrated increased vascularized bone over cell-free scaffolds after 12 weeks. While these results hold true for the CPC scaffolds, the response might vary depending upon different material compositions and topography, source of stem cells, their differentiation protocols employed, genetic modifications induced in cells, if any. Therefore, a standard consensus on the most optimal strategy for the application of stem cell technology in bone tissue engineering still remains elusive $(112,113)$.

Another critical aspect that can dictate the course of stem cell differentiation is the choice of scaffold used. Since bone is primarily composed of calcium phosphate, ceramics and ceramicglasses like hydroxyapatite (HA) (114), tricalcium phosphate (115), bioactive glass (116) have been extensively used for treating bone injuries. Since ceramics on their own are brittle, combining HA with various scaffold formulations made of polymers (both natural and synthetic) such as HA-chitosan (117), HAchitosan-polycaprolactone (118), HA-silk (119, 120) can fabricate biocomposites that possess hierarchical resemblance to native bone tissue. Also, recent applications in the field have also incorporated nanostructured ceramics and polymers with patterned topography for guided cell differentiation (121). Nanoparticles developed using this technology not only serves as mechanical strength inducers for scaffold fabrication (122), they have profound applications in stem cell tracking with promising applications in leukemia (123).

While most of the commercial bone grafting materials such as titanium plates, hydroxyapatite, bioactive glasses and polymers fail to cater to the needs of individual patients due to their standardized production. Therefore, the field of bone tissue engineering has advanced 
towards 3D (124) and 4D (135) bioprinting of encapsulated stem cells to enable development of custom-made, on-demand, personalized bone grafts. With the powerful tool of reprogrammable stem cell technology combined with improved materials and 3D/4D fabrication strategies, regenerating complete functional limbs may even become possible.

\section{Neuronal tissue engineering}

Nerve diseases including acute injury caused by mechanical, thermal, chemical or ischemic factors such as peripheral nerve injury (PNI), spinal cord injury (SCI) and traumatic brain injury (TBI), and chronic disease like neurodegeneration disease can damage the nervous system and impair system functions like memory, cognition, language and voluntary movement (126).

Despite advances in microsurgical techniques and a progressive understanding of pathophysiological mechanisms, peripheral nerve repair continues to be a major clinical challenge.

The gold standard method for repairing damaged peripheral nerves is the nerve autograft. This is not an ideal method because of donor site morbidity, the requirement for additional surgery, and limited donor tissue availability. These limitations of autograft have led to the development of alternative therapies. The use of tissue engineering to construct artificial nerves that mimics the nerve autograft provides a potentially innovative solution for peripheral nerve repair (126).

Among the various forms of scaffolds highly porous electrospun nanofiber matrices are a logical choice because of the physical and structural similarities to the extracellular matrix (ECM) components such as collagen fibers and their high surface area.

Several studies have shown that MSCs, human (h) hASCs, nerve precursor cells (NPCs), neural stem cells or Schwann cells (SCs) in combination with electrospun nanofibrous scaffolds have the potential of neural tissue regeneration (126). SCs are the principal glial cells of the peripheral nervous system which are responsible for secretion of basement membrane ECM, neurotropic factors and cell surface adhesion molecule synthesis. Therefore, an ideal scaffold onto which SCs attach, proliferate, and migrate plays a key role in neural tissue engineering (127). Among the various physical structures that can impart to improve neural regeneration, nanofiber orientation has been shown to increase ECM production. Alignment of nanofiber has been reported to greatly influence cell growth and related functions in different cell sources such as neurons and human coronary artery smooth muscle cell (SMCs) (127). It has been reported in different studies that, unidirectional aligned nanofibers can provide better contact guidance effects towards neurite outgrowth and help in providing cues to enhance SCs extension and axon regeneration.

\section{Cardiac tissue engineering (CTE)}

Cardiovascular diseases (CVDs) are the leading cause of death in the developed world, and there is a soaring need for heart transplant as the ultimate treatment option left for many who suffer from end-stage heart failure. The common CVDs such as atherosclerosis, rheumatic fever, congenital malformations and thrombosis, they all cause damage to the heart muscle. Unfortunately, the damage is irreversible because the heart muscle cells, cardiomyocytes, are thought to be terminally differentiated and non-proliferative, which necessarily limits the regenerative potential of the heart (128).

CTE involves the growth of functional cardiac tissue in vitro on biomaterial scaffolds for regenerative medicine application in cardiac diseases (129). This strategy relies on the optimization of the complex relationship between cell networks and biomaterial properties. 
Heart is a muscular hollow organ; its ECM morphology and elasticity regulate cell shape and coordinate myofibril assembly, thereby influencing tissue architecture and contractile strength (127). In CTE, biomaterials serve as scaffolds for tissue formation and vehicles for the delivery of stem cells or cardiomyocytes. Scaffolds for CTE require a number of criteria to be carefully considered to allow for optimal tissue function including: physical properties of the polymer (e.g. strength and elasticity), degradation rates, and host immune response. Natural polymers such as alginate and collagen are most commonly used as scaffolds for CTE due to their availability and biocompatibility. In synthetic materials, FDA approved polyesters such as polycaprolactone, poly-L-lactic and poly (lacticco-glycolic) acids are commonly used as they meet the most of the requirement of cardiac tissue (128). To satisfy the functional characteristics of heart, the ideal cardiac biomaterial should account for several design parameters. It should match the mechanical properties of the myocardium. A cardiac patch of rigid and inelastic biomaterial will impede heart contraction and a too soft cardiac scaffold cannot be used for mechanically reinforcing the myocardium in pathological cardiac dilation $(129,130)$.

Recently, rat (130) and human (131) decellularized heart scaffolds have been shown to support the attachment, alignment and survival of rat neonatal cardiomyocytes and human mesenchymal bone marrow derived stem cells.

\section{Future Prospects}

hMSCs hold immense translational potential in the field of regenerative medicine. All the aspects described in this review are very crucial to establish the efficacy of hMSCs in treating degenerative and immunological diseases. In tissue engineering, directing the cells to differentiate at the appropriate time, in the appropriate place, and into the most appropriate phenotype, requires an optimum environment that governs cellular processes in vivo. Future directions in hMSCs and tissue engineering will involve elucidation of molecular mechanisms by which all types of external cues influence stem cells' behaviour, followed by translation of these findings to clinical applications. Further advances in controlling stem cell fate can be achieved by combining the above mentioned parameters in a more scalable and combinatorial manner to address the complexity of the natural stem cell niche.

\section{References}

1. Friedenstein AJ, Piatetzky S II, Petrakova KV (1966). Osteogenesis in transplants of bone marrow cells. J Embryol Exp Morphol 16: 381-390.

2. Friedenstein AJ, Petrakova KV, Kurolesova AI, Frolova GP (1968). Heterotopic of bone marrow: analysis of precursor cells for osteogenic and hematopoietic tissues. Transplantation 6 : 230-247.

3. Friedenstein AJ, Chailakhjan RK, Lalykina KS (1970). The development of fibroblast colonies in monolayer cultures of guinea-pig bone marrow and spleen cells. Cell Tissue Kinet 3: 393-403.

4. Friedenstein AJ, Deriglasova UF, Kulagina NN, et al (1974). Precursors for fibroblasts in different populations of hematopoietic cells as detected by the in vitro colony assay method. Exp Hematol 2: 83-92.

5. Friedenstein AJ, Chailakhyan RK, Gerasimov UV (1987). Bone marrow osteogenic stem cells: in vitro cultivation and transplantation in diffusion chambers. Cell Tissue Kinet 20: 263-272.

6. Howlett CR, Cave J, Williamson M, et al (1986). Mineralization in in vitro cultures of rabbit marrow stromal cells. Clin Orthop Relat Res 213: 251-263. 
7. Beresford JN, Bennett JH, Devlin C, Leboy PS, Owen ME (1992). Evidence for an inverse relationship between the differentiation of adipocytic and osteogenic cells in rat marrow stromal cell cultures. J Cell Sci 102: 341-351.

8. Rickard DJ, Sullivan TA, Shenker BJ, Leboy PS, Kazhdan I (1994). Induction of rapid osteoblast differentiation in rat bone marrow stromal cell cultures by dexamethasone and BMP-2. Dev Biol 161: 218-228.

9. Cheng SL, Yang JW, Rifas L, Zhang SF, Avioli LV (1994). Differentiation of human bone marrow osteogenic stromal cells in vitro: induction of the osteoblast phenotype by dexamethasone. Endocrinology 134: 277-286.

10. Johnstone B, Hering TM, Caplan AI, Goldberg VM, Yoo JU (1998). In vitro chondrogenesis of bone marrow-derived mesenchymal progenitor cells. Exp Cell Res 238: 265-272.

11. Mackay AM, Beck SC, Murphy JM, et al (1998). Chondrogenic differentiation of cultured human mesenchymal stem cells from marrow. Tissue Eng 4: 415-428.

12. Lanotte M, Scott D, Dexter TM, Allen TD (1982). Clonal preadipocyte cell lines with different phenotypes derived from murine marrow stroma: factors influencing growth and adipogenesis in vitro. $J$ Cell Physiol 111: 177-186.

13. Wakitani S, Saito T, Caplan AI (1995). Myogenic cells derived from rat bone marrow mesenchymal stem cells exposed to 5-azacytidine. Muscle Nerve 18: 14171426.

14. Dominici M, Le Blanc K, Mueller I, et al (2006). Minimal criteria for defining multipotent mesenchymal stromal cells.
The International Society for Cellular Therapy position statement. Cytotherapy 8(4): 315-317.

15. Aggarwal S, Pittenger MF (2005). Human mesenchymal stem cells modulate allogeneic immune cell responses. Blood 105: 1815-1822.

16. Griffin MD, Elliman SJ, Cahill E, English K, Ceredig R, Ritter T (2013). Concise review: adult mesenchymal stromal cell therapy for inflammatory diseases: how well are we joining the dots? Stem Cells 31(10):2033-2041.

17. Cutler AJ, Limbani V, Girdlestone J, Navarrete CV (2010). Umbilical cordderived mesenchymal stromal cells modulate monocyte function to suppress $\mathrm{T}$ cell proliferation. J Immunol 185(11):6617-6623.

18. Ding DC, Chou HL, Chang YH, Hung WT, Liu HW, Chu TY (2016). Characterization o f H L A - G a n d r e 1 a t e d immunosuppressive effects in human umbilical cord stroma- derived stem cells. Cell Transplant 25(2):217-228.

19. Wei X, Yang X, Han ZP, Qu FF, Shao L, Shi YF (2013). Mesenchymal stem cells: a new trend for cell therapy. Acta Pharmacol Sin 34(6): 747-754.

20. Yeo RY, Lai RC, Tan KH, Lim SK (2013). Exosome: A novel and safer therapeutic refinement of mesenchymal stem. $J$ Circulating Biomarkers 1:1-12.

21. Sanchez-Ramos J, Song S, CardozoPelaez F, et al (2000). Adult bone marrow stromal cells differentiate into neural cells in vitro. Exp Neurol 164: 247-256.

22. Woodbury D, Schwarz EJ, Prockop DJ, Black IB (2000). Adult rat and human bone marrow stromal cells differentiate into neurons. J Neurosci Res 61: 364- 370. 
23. Suon S, Yang M, Iacovitti L (2006). Adult human bone marrow stromal spheres express neuronal traits in vitro and in a rat model of Parkinson's disease. Brain Res 1106: 46-51.

24. Kan I, Ben-Zur T, Barhum Y, et al (2007). Dopaminergic differentiation of human mesenchymal stem cells-utilization of bioassay for tyrosine hydroxylase expression. Neurosci Lett 419: 28-33.

25. Barzilay R, Kan I, Ben-Zur T, et al (2008). Induction of human mesenchymal stem cells into dopamine-producing cells with different differentiation protocols. Stem Cells Dev 17: 547-554.

26. Tio M, Tan KH, Lee W, Wang TT, Udolph G (2010). Roles of db-cAMP, IBMX and $\mathrm{RA}$ in aspects of neural differentiation of cord blood derived mesenchymal-like stem cells. PLoS ONE 5(2), e9398.

27. Kim JH, Auerbach JM, Rodriguez-Gomez JA, et al (2002). Dopamine neurons derived from embryonic stem cells function in an animal model of Parkinson's disease. Nature 418: 50-56.

28. Jiang Y, Henderson D, Blackstad M, et al (2003). Neuroectodermal differentiation from mouse multipotent adult progenitor cells. Proc Natl Acad Sci USA 100: 1185411860.

29. Khoo ML, Tao H, Meedeniya AC, Mackay-Sim A, Ma DD (2011). Transplantation of neuronal-primed human bone marrow mesenchymal stem cells in hemiparkinsonian rodents. PLOS ONE 6: e19025.

30. Nandy SB, Mohanty S, Singh M, Behari M, Airan B (2014). Fibroblast Growth Factor-2 alone as an efficient inducer for differentiation of human bone marrow mesenchymal stem cells into dopaminergic neurons. J Biomed Sci 21:83.
31. Zhang Z, Wang X, Wang S (2008). Isolation and characterization of mesenchymal stem cells derived from bone marrow of patients with Parkinson's disease. In Vitro Cell Dev Biol Anim 44: 169-177.

32. Trzaska KA, Kuzhikandathil EV, Rameshwar P (2007). Specification of a dopaminergic phenotype from adult human mesenchymal stem cells. Stem Cells 25: 2797-2808.

33. Fu YS, Cheng YC, Lin MY, et al (2006). Conversion of human umbilical cord mesenchymal stem cells in Wharton's jelly to dopaminergic neurons in vitro: potential therapeutic application for Parkinsonism. Stem Cells 24: 115-124.

34. PetschnikAE, Fell B, Tiede S, et al (2011). A novel xenogeneic co-culture system to examine neuronal differentiation capability of various adult human stem cells. PLOS ONE 6(9) : e24944.

35. Kim SS, Yoo SW, Park TS, et al (2008). Neural induction with neurogenin I increases the therapeutic effects of mesenchymal stem cells in the ischemic brain. Stem Cells 26: 2217-2228.

36. Trzaska KA, Reddy BY, Munoz JL, Li KY, Ye JH, Rameshwar P (2008). Loss of RE1 silencing factor in mesenchymal cell derived dopamine progenitors induces functional maturity. Mol Cell Neurosci 39: 285-290.

37. Wernig M, Zhao JP, Pruszak J, et al (2008). Neurons derived from reprogrammed fibroblasts functionally integrate into the fetal brain and improve symptoms of rats with Parkinson's disease. Proc Natl Acad Sci (USA) 105(15) : 5856- 5861.

38. Hu BY, Weick JP, Yu J, et al (2010). Neural differentiation of human induced pluripotent stem cells follows developmental principles but with variable potency. Proc Natl Acad Sci (USA): 107(9) : 4335- 4340. 
39. Yim EK, Pang SW, Leong KW (2007). Synthetic nanostructures inducing differentiation of human mesenchymal stem cells into neuronal lineage. Exp Cell Res 313(9): 1820-1829.

40. Carlberg B, Axell MZ, Nannmark U, Liu J, Kuhn HG (2009). Electrospun polyurethane scaffolds for proliferation and neuronal differentiation of human embryonic stem cells. Biomed Mater 4(4): 045004.

41. Gardin C, Vindigni V, Bressan E, et al (2011). Hyaluronan and fibrin biomaterial as scaffolds for neuronal differentiation of adult stem cells derived from adipose tissue and skin. Int J Mol Sci 12 : 67496763.

42. Yang LY, Liu XM, Sun B, Hui GZ, Fei J, Guo LH (2004). Adipose tissue-derived stromal cells express neuronal phenotypes. Chin Med J (Engl) 117(3):425-429.

43. Kingham PJ, Kalbermatten DF, Mahay D, Armstrong SJ, Wiberg M, Terenghi G (2007). Adipose-derived stem cells differentiate into a Schwann cell phenotype and promote neurite outgrowth in vitro. Exp Neurol 207(2):267-274.

44. Ning H, Lin G, Fandel T, Banie L, Lue TF, Lin CS (2008). Insulin growth factor signaling mediates neuron-like differentiation of adipose-tissue-derived stem cells. Differentiation 76(5):488-494.

45. Safford KM, Hicok KC, Safford SD, et al (2002). Neurogenic differentiation of murine and human adipose derived stromal cells. Biochem Biophys Res Commun 294(2):371-379.

46. Safford KM, Safford SD, Gimble JM, Shetty AK, Rice HE (2004). Characterization of neuronal/glial differentiation of murine adipose-derived adult stromal cells. Exp Neurol 187(2):319-328.

47. Croft AP, Przyborski SA (2006). Formation of neurons by non-neural adult stem cells: potential mechanism implicates an artifact of growth in culture. Stem Cells 24(8):1841-1851.

48. Xiong N, Zhang Z, Huang J, et al (2011). VEGF expressing human umbilical cord mesenchymal stem cells, an improved therapy strategy for Parkinson's Disease. Gene Ther 18 : 394-402.

49. Aanismaa R, Hautala J, Vuorinen A, Miettinen S, Narkilahti S (2012). Human dental pulp stem cells differentiate into neural precursors but not into mature functional neurons. Stem Cell Discovery 2(3): 85-91.

50. Lee S-H, Lumelsky N, Studer L, Auerbach JM, McKay RD (2000). Efficient generation of midbrain and hindbrain neurons from mouse embryonic stem cells. Nature Biotechnol 18: 675-679.

51. Raake P, von Degenfeld G, Hinkel R, et al (2004). Myocardial gene transfer by selective pressure-regulated retrofusion of coronary veins: comparison with surgical and percutaneous intramyocardial gene delivery. J Am Coll Cardiol 44:1124-1129.

52. Kaur K, Yang J, Eisenberg CA, Eisenberg LM (2014). 5-azacytidine promotes the transdifferentiation of cardiac cells to skeletal myocytes. Cell Reprogram 16:324-330.

53. Koyanagi M, Brandes RP, Haendeler J, Zeiher AM, Dimmeler S (2005). Cell-tocell connection of endothelial progenitor cells with cardiac myocytes by nanotubes: a novel mechanism for cell fate changes? Circ Res 96:1039-1041. 
54. Cselenyak A, Pankotai E, Horváth EM, Kiss L, Lacza Z (2010). Mesenchymal stem cells rescue cardiomyoblasts from cell death in an in vitro ischemia model via direct cell-to-cell connections. BMC Cell Biology 11:29.

55. Yong SK, Ahn Y, Kwon JS, et al (2012). Priming of mesenchymal stem cells with oxytocin enhances the cardiac repair in ischemia/reperfusion injury. Cells Tissues Organs 195:428-442.

56. Mohanty S, Bose S, Jain KG, et al (2013). TGF- $\beta 1$ contributes to cardiomyogeniclike differentiation of human bone marrow mesenchymal stem cells. Int $J$ Cardiol 163:93-99.

57. Kakkar A, Mohanty S, Bhargava B, Airan B (2015). Role of human cardiac biopsy derived conditioned media in modulating bone marrow derived mesenchymal stem cells toward cardiomyocyte-like cells. $J$ Pract Cardiovasc Sci 1:150-155.

58. He XQ, Chen MS, Li SH, et al (2010). Coculture with cardiomyocytes enhanced the myogenic conversion of mesenchymal stromal cells in a dose-dependent manner. Mol Cell Biochem 339: 89-98.

59. Plotnikov EY, Khryapenkova TG, Vasileva AK, et al (2008). Cell-to-cell cross-talk between mesenchymal stem cells and cardiomyocytes in co-culture. $J$ Cell Mol Med 12:1622-1631.

60. Berry MF, Engler AJ, Woo YJ, et al (2006). Mesenchymal stem cell injection after myocardial infarction improves myocardial compliance. Am J Physiol Heart Circ Physiol 290: H2196-H2203.

61. Makkar RR, Smith RR, Cheng K, et al (2012). Intracoronary cardiospherederived cells for heart regeneration after myocardial infarction (CADUCEUS): a prospective, randomised phase 1 trial. Lancet 379:895-904.

62. Petrakova KV, Tolmacheva AA, Fridenshtein A (1963). Bone formation occurring in bone marrow transplantation in diffusion chambers. Biull Eksp Biol $\operatorname{Med}$ 56:87-91.

63. Rawadi G, Vayssiere B, Dunn F, Baron R, Roman-Roman S (2003). BMP-2 controls alkaline phosphatase expression and osteoblast mineralization by a Wnt autocrine loop. J Bone Miner Res 18: $1842-1853$.

64. Cheng H, Jiang W, Phillips FM, et al (2003). Osteogenic activity of the fourteen types of human bone morphogenetic proteins (BMPs). J Bone Joint Surg Am 85:1544-1552.

65. Spinella-Jaegle S, Roman-Roman S, Faucheu C, et al (2001). Opposite effects of bone morphogenetic protein-2 and transforming growth factor-beta1 on osteoblast differentiation. Bone 29:323330 .

66. de Jong DS, van Zoelen EJ, Bauerschmidt S, Olijve W, Steegenga WT (2002). Microarray analysis of bone morphogenetic protein, transforming growth factor beta, and activin early response genes during osteoblastic cell differentiation. J Bone Miner Res 17:2119-2129.

67. Taguchi Y, Yamamoto M, Yamate T, et al (1998). Interleukin-6-type cytokines stimulate mesenchymal progenitor differentiation toward the osteoblastic lineage. Proc Assoc Am Physicians 110:559-574.

68. Kroger H, Soppi E, Loveridge N (1997). Growth hormone, osteoblasts, and marrow adipocytes: a case report. Calcif Tissue Int 61:33-35. 
69. Thomas T, Gori F, Khosla S, Jensen MD, Burguera B, Riggs BL (1999). Leptin acts on human marrow stromal cells to enhance differentiation to osteoblasts and to inhibit differentiation to adipocytes. Endocrinology 140:1630-1638.

70. Maeda S, Nobukuni T, Shimo-Onoda K, et al (2002). Sortilin is upregulated during osteoblastic differentiation of mesenchymal stem cells and promotes extracellular matrix mineralization. $J$ Cell Physiol 193:73-79.

71. Nurminskaya M, Magee C, Faverman L, Linsenmayer TF (2003). Chondrocytederived transglutaminase promotes maturation of preosteoblasts in periosteal bone. Dev Bio 263:139-152.

72. Sottile V, Thomson A, McWhir J (2003). In vitro osteogenic differentiation of human ES cells. Cloning Stem Cells 5:149-155.

73. Gupta A, Leong DT, Bai HF, Singh SB, Lim TC, Hutmacher DW (2007). Osteomaturation of adipose-derived stem cells required the combined action of vitamin D3, beta-glycerophosphate, and ascorbic acid. Biochem Biophys Res Commun 362:17-24.

74. Zur Nieden NI, Kempka G, Ahr HJ (2003). In vitro differentiation of embryonic stem cells into mineralized osteoblasts. Differentiation 71:18-27.

75. Raisz LG, Pilbeam CC, Fall PM (1993). Prostaglandins: mechanisms of action and regulation of production in bone. Osteoporos Int 3(Suppl 1):136-140.

76. Weinreb M, Grosskopf A, Shir N (1999). The anabolic effect of PGE2 in rat bone marrow cultures is mediated via the EP4 receptor subtype. Am J Physiol 276:E376E383.
77. Van Leeuwen JP, van Driel M, van den Bemd GJ, Pols HA (2001). Vitamin D control of osteoblast function and bone extracellular matrix mineralization. Crit Rev Eukaryot Gene Expr 11:199-226.

78. Notoya K, Nagai H, Oda T, et al (1999). Enhancement of osteogenesis in vitro and in vivo by a novel osteoblast differentiation promoting compound, TAK-778. J Pharmacol Exp Ther 290:1054-1064.

79. Sugiyama M, Kodama T, Konishi K, Abe K, Asami S, Oikawa S (2000). Compactin and simvastatin, but not pravastatin, induce bone morphogenetic protein-2 in human osteosarcoma cells. Biochem Biophys Res Commun 271:688-692.

80. Phillips BW, Belmonte N, Vernochet C, Ailhaud G, Dani C (2001). Compactin enhances osteogenesis in murine embryonic stem cells. Biochem Biophys Res Commun 284:478-484.

81. Yourek G, McCormick SM, Mao JJ, Reilly GC (2010). Shear stress induces osteogenic differentiation of human mesenchymal stem cells. Regen Med 5(5):713-724.

82. Jansen JH, van der Jagt OP, Punt BJ, et al (2010). Stimulation of osteogenic differentiation in human osteoprogenitor cells by pulsed electromagnetic fields: an in vitro study. BMC Musculoskelet Disord 11:188-199.

83. Hess R, Douglas T, Myers KA, et al (2010). Hydrostatic pressure stimulation of human mesenchymal stem cells seeded on collagen-based artificial extracellular matrices. JBiomech Eng 132(2):1-6.

84. Lee KS, Kim HJ, Li QL, et al (2000). Runx 2 is a common target of transforming growth factor beta 1 and bone morphogenetic protein 2 , and cooperation 
between Runx2 and Smad5 induces osteoblast-specific gene expression in the pluripotent mesenchymal precursor cell line C2C12. Mol Cell Biol 20(23):87838792.

85. Lee MH, Kim YJ, Kim HJ, et al (2003). BMP-2-induced Runx2 expression is mediated by Dlx5, and TGF- $\beta 1$ opposes the BMP-2-induced osteoblast differentiation by suppression of Dlx 5 expression. $J$ Biol Chem 278(36):3438734394.

86. Matsubara T, Kida K, Yamaguchi A, et al (2008). BMP2 regulates osterix through Msx2 and Runx2 during osteoblast differentiation. J Biol Chem 283(43):29119-29125.

87. Harada S, Rodan GA (2003). Control of osteoblast function and regulation of bone mass. Nature 423(6937):349-355.

88. Zippel N, Limbach CA, Ratajski N, et al (2012). Purinergic receptors influence the differentiation of human mesenchymal stem cells. Stem Cells Dev 21(6):884-900.

89. Komori T (2006). Regulation of osteoblast differentiation by transcription factors. J Cell Biochem 99(5):1233-1239.

90. Liu W, Toyosawa S, Furuichi T, et al (2001). Overexpression of Cbfa1 in osteoblasts inhibits osteoblast maturation and causes osteopenia with multiple fractures. JCell Biol 155(1):157-166.

91. Nakashima K, Zhou X, Kunkel G, et al (2002). The novel zinc finger-containing transcription factor Osterix is required for osteoblast differentiation and bone formation. Cell 108(1): 17-29.

92. Aubin JE, Liu F (1996). The osteoblast lineage. In: Principles of Bone Biology. Bilezikian JP, Raisz LG, Rodan GA, eds. San Diego, California, USA: Academic Press, 51-67.
93. Pavlin D, Dove SB, Zadro R, GluhakHeinrich J (2000). Mechanical loading stimulates differentiation of periodontal osteoblasts in a mouse osteoinduction model: effect on type I collagen and alkaline phosphatase genes. Calcif Tissue Int 67(2):163-172.

94. Pavlin D, Zadro R, Gluhak-Heinrich J (2001). Temporal pattern of stimulation of osteoblast-associated genes during mechanically-induced osteogenesis in vivo: early responses of osteocalcin and type I collagen. Connect Tissue Res 42(2):135-148.

95. Aggarwal S, Pittenger MF (2005). Human mesenchymal stem cells modulate allogeneic immune cell responses. Blood $105: 1815-1822$.

96. Ilancheran S, Moodley Y, Manuelpillai U (2009). Human fetal membranes: a source of stem cells for tissue regeneration and repair? Placenta 30(1):2-10.

97. Gonzalez-Hernandez A, LeMaoult J, Lopez A, et al (2005). Linking two immuno-suppressive molecules: indoleamine 2,3 dioxygenase can modify HLA-G cell-surface expression. Biol Reprod 73: 571-578.

98. Nasef A, Mazurier C, Bouchet S, et al (2008). Leukemia inhibitory factor: role in human mesenchymal stem cells mediated immunosuppression. Cell Immunol 253: 16-22.

99. Ding DC, Chou HL, Chang YH, Hung WT, Liu HW, Chu TY (2016). Characterization o f H L A - G a n d r e 1 a t e d immunosuppressive effects in human umbilical cord stroma-derived stem cells. Cell Transplant 25: 217-218.

100. Griffin MD, Elliman SJ, Cahill E, English K, Ceredig R, Ritter T (2013). Concise 
review: adult mesenchymal stromal cell therapy for inflammatory diseases: how well are we joining the dots? Stem Cells 31(10):2033-2041.

101. Cutler AJ, Limbani V, Girdlestone J, Navarrete CV (2010). Umbilical cordderived mesenchymal stromal cells modulate monocyte function to suppress $\mathrm{T}$ cell proliferation. J Immunol 185(11):6617-6623.

102. Hsuan $\mathrm{YC}$, Lin $\mathrm{CH}$, Chang CP, Lin MT (2016). Mesenchymal stem cell-based treatments for stroke, neural trauma, and heat stroke. Brain Behav 6(10): e00526.

103. Patel DM, Shah J, Srivastava AS (2013). Therapeutic potential of mesenchymal stem cells in regenerative medicine. Stem Cells Int 2013: Article ID 496218, 15 pages.

104. Hu G, Drescher KM, Chen XM (2012). Exosomal miRNAs: biological properties and therapeutic potential. Front Genet 3 $: 56$.

105. Yu B, Zhang X, Li X (2014). Exosomes derived from mesenchymal stem cells. Int J Mol Sci 15 :4142-4157.

106. Katsuda T, Tsuchiya R, Kosaka N, et al (2013). Human adipose tissue-derived mesenchymal stem cells secrete functional neprilysin-bound exosomes. Sci Rep 3: 1197.

107. Seong JM, Kim BC, Park JH, Kwon IK, Mantalaris A, Hwang YS (2010). Stem cells in bone tissue engineering. Biomed Mater 5(6): 062001.

108. Wang P, Liu X, Zhao L, et al (2015). Bone tissue engineering via human induced pluripotent, umbilical cord and bone marrow mesenchymal stem cells in rat cranium. Acta Biomaterialia 18: 236-248.
109. Shao J, Zhang W, Yang T (2015). Using mesenchymal stem cells as a therapy for bone regeneration and repairing. Biol Res $48: 62$.

110. Wu Q, Yang B, Hu K, Cao C, Man Y, Wang $\mathrm{P}$ (2017). Deriving osteogenic cells from induced pluripotent stem cells for bone tissue engineering. Tissue Eng Part B Rev 23(1): 1-8.

111. Zhu W, Wang D, Xiong J, et al (2015). Study on clinical application of nanohydroxyapatite bone in bone defect repair. Artif Cells Nanomed Biotechnol 43(6): 361-365.

112. Gao P, Zhang H, Liu Y, et al (2016). Betatricalcium phosphate granules improve osteogenesis in vitro and establish innovative osteo-regenerators for bone tissue engineering in vivo. Sci Rep 6 :23367.

113. Midha S, Kim TB, van den Bergh W, Lee PD, Jones JR, Mitchell CA (2013). Preconditioned 70S30C bioactive glass foams promote osteogenesis in vivo. Acta Biomater 9(11): 9169-9182.

114. Kong L, Gao Y, Cao W, Gong Y, Zhao N, Zhang $X$ (2005). Preparation and characterization of nanohydroxyapatite/chitosan composite scaffolds. J Biomed Mater Res A 75(2): 275-282.

115. Jain KG, Singh M, Kakkar A, et al (2017). Evaluating the osteogenic potential of CHT/HAP/PCL biocomposites in bone tissue engineering: an in vivo study. Int $J$ SciRes 6(5): 10-13.

116. Huang X, Bai S, Lu Q, Liu X, Liu S, Zhu H (2015). Osteoinductive-nanoscaled silk/HA composite scaffolds for bone tissue engineering application. $J$ Biomed Mater Res B Appl Biomater 103(7): 1402-1414. 
117. Sun L, Parker ST, Syoji D, Wang X, Lewis JA, Kaplan DL (2012). Direct-write assembly of $3 \mathrm{D}$ silk/hydroxyapatite scaffolds for bone co-cultures. $A d v$ Healthcare Mater 1 : 729-735.

118. Walmsley GG, McArdle A, Tevlin R, et al (2015). Nanotechnology in bone tissue engineering. Nanomedicine 11(5) :12531263.

119. Aston DE, Bow JR, Gangadean DN (2013). Mechanical properties of selected nanostructured materials and complex bio-nano, hybrid and hierarchical systems. Int Mater Rev 58(3): 167-202.

120. Edmundson M, Thanh NT, Song B (2013). Nanoparticles based stem cell tracking in regenerative medicine. Theranostics $\mathbf{3 ( 8 )}$ : 573-582.

121. Byambaa B, Annabi N, Yue K, et al (2017). Bioprinted osteogenic and vasculogenic patterns for engineering 3D bone tissue. Adv Healthc Mater 6(16): $1-15$.

122. Gladman AS, Matsumoto EA, Nuzzo RG, Mahadevan L, Lewis JA (2016). Biomimetic 4D printing. Nat Mater 15(4): 413-418.

123. Tian L, Prabhakaran MP, Ramakrishna S (2015). Strategies for regeneration of components of nervous system: scaffolds, cells and biomolecules. Regen Biomater 2(1): $31-45$.

124. Masaeli E, Morshed M, Nasr-Esfahani $\mathrm{MH}$, et al (2013). Fabrication, characterization and cellular compatibility of poly(hydroxy alkanoate) composite nanofibrous scaffolds for nerve tissue engineering. PLOS ONE 8(2): e57157.
125. Reis LA, Chiu LL, Feric N, Fu L, Radisic M (2016). Biomaterials in myocardial tissue engineering. J Tissue Eng Regen Med 10(1): 11-28.

126. Huyer LD, Montgomery M, Zhao Y, et al (2015). Biomaterial based cardiac tissue engineering and its applications. Biomed Mater 10(3): 034004.

127. Chen FM, Liu X (2016). Advancing biomaterials of human origin for tissue engineering. Prog Polym Sci 53: 86-168.

128 Nagueh SF, Shah G, Wu Y, et al (2004). Altered titin expression, myocardial stiffness, and left ventricular function in patients with dilated cardiomyopathy. Circulation 110:155-162.

129. Weis SM, Emery JL, Becker KD, McBride DJ, Omens JH, McCulloch AD (2000). Myocardial mechanics and collagen structure in the osteogenesis imperfecta murine (oim). Circ Res 87:663-669.

130. Ott HC, Matthiesen TS, Goh SK, et al (2008). Perfusion-decellularized matrix: using nature's platform to engineer a bioartificial heart. Nat Med 14:213-221.

131. Sanchez PL, Fernandez-Santos ME, Costanza S, et al (2012). Characterization and biocompatibility of perfusiondecellularized human heart matrix: toward bioengineering perfusable human heart grafts. J Am Coll Cardiol 59:E857-E857. 